\title{
Poverty Alleviation Fund in Financial Inclusions of Nepal
}

By K.C. Nahakul

Mr. KC is PhD Scholar of Rural Development Department of Tribhuvan University Nepal. Contact at: nahakulkc@gmail.com

\begin{abstract}
This research was an attempt to take a deeper look at people's experience of existing financial services and their providers. In addition, it aimed to identify definitive indicators that would help to create a roadmap for the delivery of effective financial services in Nepal. The study emphasized that ensuring financial inclusion is an arduous task and requires a holistic approach encompassing strategies for awareness raising, financial education, technical advice on different dimensions of money management, debt counseling, saving mobilization, provision of affordable credit services, research and development. In order to promote financial inclusion, there is a need to develop and apply specific strategies to expand the outreach of their services using combinations of lending methodologies, market led approaches to new product development, fostering linkages with local communities and promoting the use of technologies. This paper is basically descriptive and analytical in nature and based on a number of policy models and provisions formulated in recent years for promoting financial inclusion in Nepal. Secondary data is used, drawn primarily from, Poverty Alleviation Fund, Department of Co-operatives and different departments. Micro finance institutions should give equal priority for non-financial services such as financial literacy and provision of entrepreneurship skills through government and non-government organizations that ultimately helps to utilize micro-credit into productive sectors.
\end{abstract}

Keywords: Financial Inclusion, Poverty Alleviation Fund

\section{Introduction}

The Poverty Alleviation Fund (PAF) was established in 2003 under the special Act of the Parliament. This specially designed institutional modality to implement targeted programs of the GoN is to improve living conditions, livelihoods and empowerment of the rural poor, with particular attention to groups that have traditionally been discriminated and excluded on the basis of gender, ethnicity, caste and geographic location. The PAF model takes a Community Demand Driven (CDD) approach and supports the formation of representative community organizations (CO) of the poor and helps them identify their own development priorities, needs and solutions. Revolving fund for income generations, saving credit mobilization, infrastructure projects that 
support the Income Generation (IG) activities and infrastructure projects that benefit the larger communities has been the key components of this modality (Regmi, et al., 2018). It was expedient to provide for legal provisions to establish and operate a Fund related to poverty alleviation, for causing to implement various programs related to poverty alleviation through active participation of poor and backward class of society and to alleviate poverty from the country by providing grant and necessary assistance to the institutions involved in the activities for poverty alleviation (Nepal Government, 2006)

Nepal is a small landlocked country in South Asia, with a population of approximately 28.5 million. In 2008, after a long conflict, the first Nepali Constituent Assembly ruled in favor of abolishing the monarchy. Since then, Nepal has become a federal multiparty representative democratic republic. The new political structure encountered significant and continuing challenges. The new constitution was promulgated with a resounding majority by the Constituent Assembly on September 20, 2015, but it fueled agitation and violence among aggrieved population groups, most notably the Madhesis, during the last months of 2015 until the spring of 2016 (World Bank, 2017).

The community based and driven approach has already resulted in the formation of over 21 thousand and five hundred Community organizations (COs) spread in 40 districts. Nearly 622 thousand households are direct beneficiaries, of which 75 per cent are women and 65 per cent are ultra-poor-- those who do not have food sufficiency for more than 3 months a year. PAF has been able to expand and deepen its program during the reporting year. A total of 21,617 community organizations (COs) of the poor are registered with PAF. Out of these registered COs, PAF has signed an agreement with 20,268 COs including 3,4449 COs during the reporting period to carry out different income generation and community infrastructure related initiatives (PAF, 2017 ). COs are further federated and formed co-operatives to carry out infrastructure sub-projects and link with market (PAF, 2012). Nepal Poverty Alleviation Fund is a World Bank supported community-driven development program. Its objective is to improve rural welfare, particularly for groups that have traditionally been excluded for reasons of gender, ethnicity, caste, and location. Since its launch in 2004, the Fund has covered the 40 poorest districts of the country, supported some 15,000 community organizations, and benefited more than 2.5 million people. Annual Report 2016 documents the development record of PAF in 2004-2017 in focusing on the program results in the form of development themes vis-a-vis the targets by periods, and as the cutting-edge of new concepts to empower the people. PAF has thus taken an important step forward in social transformation reaching nearly one million targeted families under the umbrella of 32,360 community organizations with their revolving fund of Rs 14 billion, infrastructure, 
utilities, and production models in the areas of agriculture, livestock, forestry, alternative energy, handicrafts, services, natural resource management, climate change adaptations, and vulnerabilitycoping mechanisms, among others. In that process, it has also served nearly two-thirds of the households living under poverty in the country, creating a huge network of social and financial capital by opening new frontiers of production and doubling the food security of the targeted people from four to eight months for a year (PAF, 2017). The guiding principles of the funds are: targeted to poor, social inclusion, community demand driven, direct community funding, community institutions and transparency

\section{Objectives}

By making financial services accessible at affordable costs to all individuals and businesses, irrespective of net worth and size, financial inclusion strives to address and offer solutions to the constraints that exclude people from participating in the financial sector. Research shows that countries with deeper levels of financial inclusion- defined as access to affordable, appropriate financial services- have stronger GDP growth rates and lower income inequality (Ravi, 2019). Therefore, to check the financial inclusion in Nepal the paper was designed the specific objective of the study is: To find out the Financial Inclusion Status of Nepalese community intervened by Poverty Alleviation Fund Nepal.

\section{Methodology}

This paper is basically descriptive and analytical in nature and based on a number of policy models and provisions formulated in recent years for promoting financial inclusion in Nepal. Secondary data is used, drawn primarily from, Poverty Alleviation Fund, Department of Co-operatives and different departments of Nepal Rastra Bank (NRB), namely Banks and Financial Institutions Regulation Department, Microfinance Promotion and Supervision Department and Research Department. Financial inclusion data is also extracted from sources such as the International Monetary Fund, United Nations Capital Development Fund (UNCDF), World Bank and World Economic Forum, among others.

\section{Discussions}

\section{Inclusion}

The inclusion data of PAF's coverage indicated that there are 79\% women, $24 \%$ Dalit, and $32 \%$ Janajatis among PAFs beneficiaries. The coverage of Dalit and other marginalized group is also satisfactory. The social inclusion part is subject to the demographic composition of the location 
itself (Regmi, et al., 2018). Tenth Plan 2002- 2007. The PRSP paper had four broad pillars: (i) generating broad-based economic growth; (ii) improving service delivery; (iii) promoting social inclusion; and (iv) improving governance. Concept of social inclusion and exclusion gained considerable leverage when Government of Nepal recognized inclusion as a policy issues as one the four pillar of 2003 Poverty Reduction Strategy Paper. The PRSP has stated four key pillars: a) achieve and sustain high and broad-based economic growth, focusing particularly in the rural economy, ii) accelerate human development through a renewed emphasis on effective delivery of basic social services and economic infrastructure, iii) ensure social and economic inclusion of the poor, marginalized groups and less developed regions by using targeted programs where appropriate and iv) pursue good governance as a means of achieving better development results and ensuring social and economic justice. PAF future strategy has an additional focus on the financial inclusion, the results are highly encouraging and show the potential high demands of PAF beneficiaries for bigger size loans through formal and regulated financial institutions. In many program districts, PAF is providing support in forming institutions like co-operatives, community organization networks, as well as supporting product development, market linkages and financial inclusion (Regmi, et al., 2018).

Networks created around similar activities led to the formation of co-operatives improving the sense of collectivism, inclusion, and social capital. The benefits of revolving funds and regular meetings in communities receiving income-generating activities were associated with the development of networks, according to community organization members interviewed in the field (World Bank, 2017). In stressing access to income-generating activities and infrastructure (and not also an increase in community well-being), the project objectives were relatively unambitious. Yet, the project design included many elements to support the achievement of its objectives and to ensure inclusion, ownership, and sustainability. The RF loan mechanism is performing well in areas of social inclusion, financial access, and asset creation, with all $\mathrm{CO}$ members accessing RF loans at least once. COs have leveraged initial RF capital for income generating activities, and a few have also mobilized savings for internal lending activities.

PAF has taken the strategy to support the idea that poor community should be organized themselves to prepare, implement and manage their program and they should be in the driving seat, with decision making authority. Participatory social assessment and community well- being ranking process identified the poor community members as primary beneficiaries at the settlement level. They are organized into community organization to plan, implement and manage their subprojects. As entry point of PAF program at settlement level, social mapping and participatory 
social assessment is the primary social (PAF, 2012). The most impressive achievement of PAF programs was made in social inclusion. Of total $\mathrm{CO}$ members, 78 percent are female and representation from Dalits, Janajatis and Muslims is $60 \%$ in the community organizations (PAF, 2016). PAF supports agenda that poor communities organize themselves to prepare, implement and manage programs, and should be in the driving seat with a decision-making authority. Participatory social assessment and community well-being ranking processes have identified the poor community members as primary beneficiaries at the settlement level. They are organized into COs to plan, implement, and manage their subprojects. As an entry point of PAF program at the settlement level, the primary step is social mapping and participatory social assessment for social mobilization. The settlement level social assessment has revealed that 65.8 percent of the $\mathrm{HHs}$ are poor, and are therefore included as $\mathrm{CO}$ members in PAF program.

\section{Financial Inclusion}

Financial Inclusion is the process of ensuring access to appropriate financial products and services needed by vulnerable groups such as weaker sections and low income groups at an affordable cost in a fair and transparent manner by mainstream Institutional players. Historically, the primary responsibility of financial inclusion in rural areas lay with the co-operative sector and commercial banks, but they were unable to bring rural populations into the fold. Informal employment, lack of collateral and the inability of rural populations to approach and negotiate with formal financial institutions, makes it easier for an entire subsection of our population to go unbanked (Ravi, 2019). Financial exclusion hence imposes large opportunity costs on those who suffer from it the most. When coupled with information asymmetries and high transaction costs, the poor who lack collateral or credit histories are stuck in a bad equilibrium with no escape. Macroeconomic evidence shows that countries with deeper financial inclusion tend to grow faster and reduce income inequality. As the Indian financial ecosystem evolves, any form of financial inclusion going forward must recognize broad needs and to study the impact of such inclusion, one must include not only policy mandates but also wider metrics. From a policy standpoint, studying such metrics will not only deepen our understanding of the impact of financial inclusion but also answer critical questions on how to achieve it. Hence, it is important to identify a full range of financial services available to the poor -- savings, credit and insurance.

Financial inclusion has moved up the global reform agenda and become a topic of great interest for policy makers, regulators, researchers, market practitioners, and other stakeholders. For the World Bank Group, financial inclusion represents a core topic, given its implications for reducing poverty and boosting shared prosperity. The increased emphasis on financial inclusion reflects 
a growing realization of its potentially transformative power to accelerate development gains. Inclusive financial systems provide individuals and firms with greater access to resources to meet their financial needs, such as saving for retirement, investing in education, capitalizing on business opportunities, and confronting shocks (World Bank, 2014). Financial inclusion is The share of individuals and firms that use financial services. Financial inclusion-typically defined as the proportion of individuals and firms that use financial services-has become a subject of considerable interest among policy makers, researchers, and other stakeholders.

\section{Experience and comparative advantage in financial inclusion}

PAF has a strong comparative advantage of its nation-wide outreach and network of Cos with financial record. PAF has so far provided almost 30,000 community organizations through the revolving fund, and many of them have acquired basic financial literacy. Some of them formed higher level institution such as SACCOs and engaged in higher amount of transactions with proven credibility and financial record. Moreover, PAF has complete data of performance monitoring of revolving fund and could provide data to the financial sector who are interested in lending to the poor segment of population under the GON's policy. PAF conducted a series of consultation meetings with Nepal Bankers Association and intends to work closely with banks and MFIs for financial inclusion (UNCDF, 2014).

(Map of Financial Inclusion in Nepal)

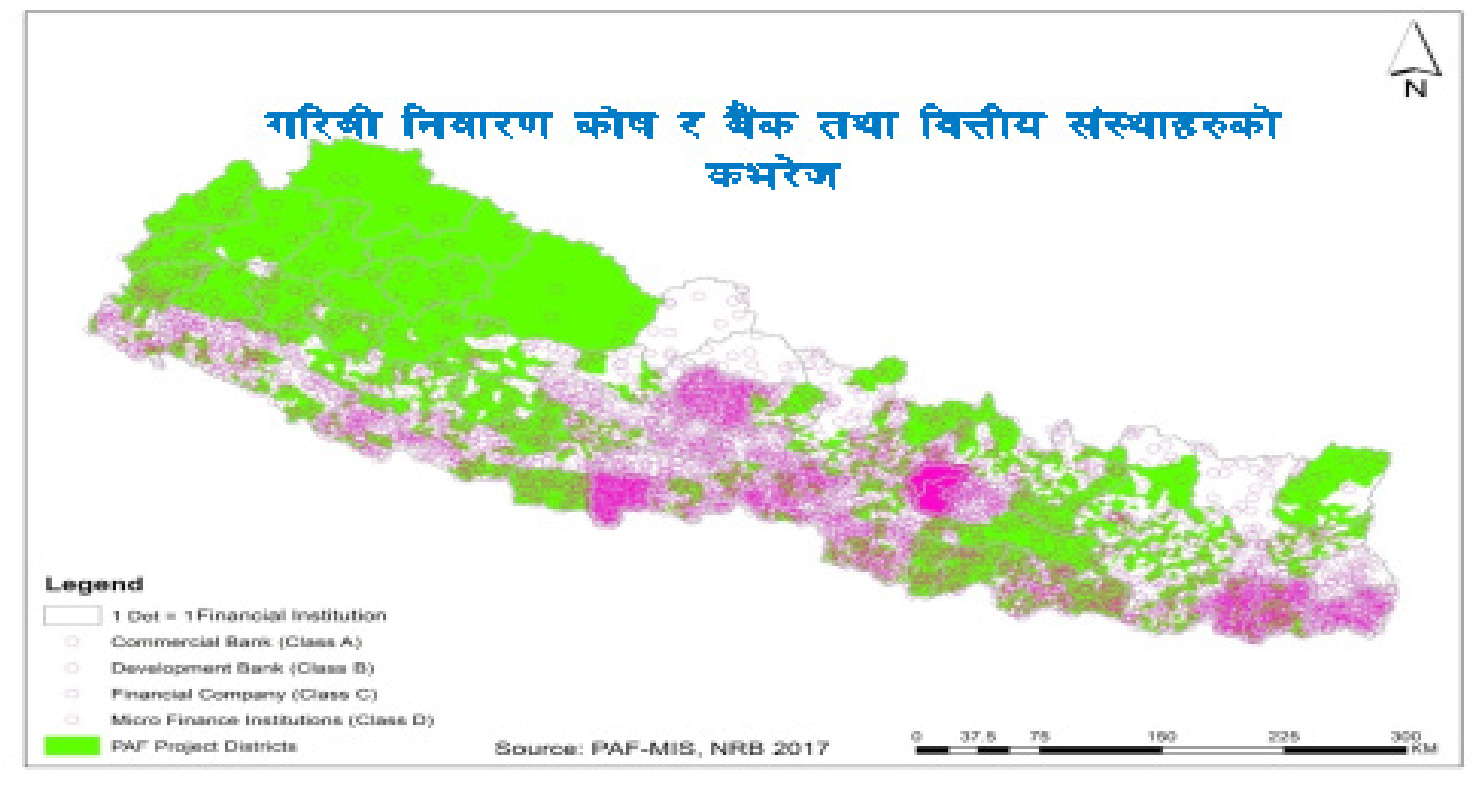


(Study, 2019)

The main objective of the financial inclusion initiatives is to work with the mainstream financial institutions to ensure affordable and reliable access to full suite of financial services to the targeted rural poor households. The suite of financial services includes financial advice and counseling services, savings, both individual and CO levels, credit, individual and CO levels, payments, including private remittances. PAF has a strong comparative advantage of its nation-wide outreach and network of COs with financial record.

PAF has so far provided almost 30,000 community organizations through the revolving fund, and many of them have acquired basic financial literacy. Moreover, PAF has complete data of performance monitoring of revolving fund and could provide data to the financial sector that are interested in lending to the poor segment of population under the GON's policy. PAF conducted a series of consultation meetings with Nepal Bankers Association and intends to work closely with banks and MFIs for financial inclusion. Some of them formed higher-level institution such as SACCOs and engaged in higher amount of transactions with proven credibility and financial record. Financial service providers in Nepal include formal entities such as banks, microfinance institutions and co-operatives, as well as informal entities such as moneylenders, unofficial groups and friends (UNCDF, 2014)

A key component of financial literacy and counseling is the business plan process. The business plans help the $\mathrm{CO}$ members to know, monitor, and effectively use financial resources to enhance their economic wellbeing and also educate them on responsible borrowing besides offering counsel on debt restructuring plans for members who are in distress. Thus far nearly $100 \%$ of the total COs i.e nearly 30,000 COs have been trained in the business plan methodology (PAF, 2016).

The premise of capitalization addresses the issue of Strengthening of community institutions, improving its dynamics and thus making it much more vibrant and decision oriented. With the progress of the PAF project the impact of Capitalization had been explicitly visible in terms of strengthened group dynamics, debt reduction of women members and mitigating other vulnerabilities like health shocks. The capitalization of group through the process of business plan indicates that there is a large credit gap felt at member level in terms of its accessibility from the mainstream financial sources. A total of nearly 28,000 COs have been capitalized thus far, along with 110 pocket areas in the form of co-operatives, commodity groups or cottage industries. Making poor the preferred clients of the banking system and mobilizing bank credit will become core to the future project financial inclusion and investment strategy. Bank linkage 
will be the main source of institutional finance for the community institutions. Consultations with the commercial banks and other financial institutions showcased that they are interested in partnerships for lending to the project based on the sound credibility of the community institutions. The project can also sensitize the local bank branch managers' fir exposure visits to places where bank linkage is successfully scaled up (Dhungana, 2018).

Commercial banks are working on the alternate banking models such as branchless banking and digital banking. The learnings from such pilot will be taken into future project to make the project lead the financial inclusion of the Government of Nepal. Micro-finance (MF) program has become a globally popular anti-poverty intervention strategy, based on group lending system and a near-exclusive focus on women. MF has become a significant part of development finance to address financial inclusion and poverty reduction in developing countries like Nepal (Dhungana, 2018). MF is a tool of financial inclusion and way of empowering people through collateral free micro-credit to initiate micro-business or enterprises. Research-both theoretical and empiricalsuggests that financial inclusion is important for development and poverty reduction. For the poor, the relevant evidence is especially strong on access to savings and automated payments; it is much weaker on access to credit. For firms, especially for small and medium enterprises and new entrepreneurs, improving access to credit is likely to have significant growth benefits (World Bank, 2014). Financial inclusion is important for development and poverty reduction.

\section{Conclusion}

Financial service providers in Nepal include formal entities such as banks, microfinance institutions and co-operatives, as well as informal entities such as moneylenders, unofficial groups and friends. The status of financial inclusion in Nepal is not satisfactory and three fourth (75.0 percent) of the people have still no bank accounts at the formal financial institutions (World Bank, 2014). Large numbers of people are still depending on the informal lending system in the country especially in hilly and rural areas due to poor financial inclusion. Unless financial inclusion is made effective, the majority of the people will be deprived of formal financial services. In fact, building an inclusive financial system is a challenging task that requires a high degree of efforts and commitment. 


\section{References}

Dhungana, B. R. (2018). Impact of Micro-Finance on Business Creation: A Case of Nepal. The Journal of Nepalese Business Studies Vol. XI No. 1 December 2018, 23-34.

Nepal Government. (2006). Poverty Alleviation Fund Act, 2063 (2006) . Kathmandu: Nepal Government.

PAF. (2012). Building Self Reliant Communities: Annual Progress Report 2012. Kathmandu: Poverty Alleviation Fund.

PAF. (2016). Poverty Alleviation Fund: Annual Report 2016. Kathmandu: Poverty Alleviation Fund .

PAF. (2017 ). Poverty Alleviation Fund: Annual Progress Report 2017. Kathmandu: Poverty Alleviation Fund Nepal.

Ravi, S. (2019). Accelerating Financial Inclusion in India . Delhi: Brookings India Report, March 2019.

Regmi, R. R., Bronfman, J., Sharma, S., Rana, S., Gautam, S., \& Adhikari, N. (2018). Comprehensive Impact Evaluetion of Poverty Alleviation Fund Nepal. Kathmandu: Poverty Alleviation Fund.

UNCDF. (2014). Understanding demand for the financial services in Nepal. Kathmandu: UN Capital Development Fund (UNCDF) .

World Bank. (2014). Global Financial Development Report 2014: Financial Inclusion. Washington, DC: World Bank. doi:10.1596/978-0-8213-9985-9.

World Bank. (2017). Nepal-Poverty Alleviation Fund Project. Independent Evaluation Group, Project Performance Assessment Report . Washington, DC: World Bank. 